\title{
Teaching and Access to Industry Standards in Canada: Experience at Queen's University and the University of Toronto
}

\author{
Sharon Murphy \\ Head, Engineering \& \\ Science Library \\ Queen’s University \\ murphys@queensu.ca
}

\author{
David S. Strong \\ NSERC Chair in Design \\ Engineering, Faculty of \\ Applied Science \\ Queen’s University \\ strongd@ilc.queensu.ca
}

\author{
Cristina Sewerin \\ Engineering \& \\ Computer Science \\ Library \\ University of Toronto \\ cris.sewerin@utoronto.ca
}

\begin{abstract}
This paper provides an exploratory overview of the current state of teaching of and access to standards, focusing on the experiences at Queen's University and at the University of Toronto. We argue that standards education is a core experience for engineering students and that it is incumbent on academic libraries to provide access to them.
\end{abstract}

\section{Introduction}

"A standard can be defined as a set of technical definitions and guidelines that function as instructions for designers, manufacturers, operators, or users of equipment. ... A standard is a code when it has been adopted by one or more governmental bodies and is enforceable by law, or when it has been incorporated into a business contract.” [1]

\section{Teaching Industry Standards}

Industry Standards are an integral and arguably critical part of professional engineering practice, regardless of engineering discipline. Codes and standards are available for the development of most processes, products, performance testing, and in some cases, software. In fact, standards exist for a vast number of products that we are exposed to every day. Practicing engineers who value safety, mitigation of liability, and in most cases, customer acceptance, would not think of undertaking an engineering project without first considering applicable standards and legislation.

Industry or "regulatory" standards are referenced in engineering accreditation documentation in both
Canada and the US. The Canadian Engineering Accreditation Board (CEAB), in its Accreditation Criteria and Procedures [2], refers to the inclusion of appropriate regulatory standards directly in reference to engineering design content (section 2.2.3), and indirectly with respect to the role and responsibility of the professional engineering in society (section 2.2.7). ABET, the Engineering Accreditation Commission in the US, goes one step further in its Criteria for Assessing Engineering Programs [3], with a stated requirement for “...incorporating appropriate engineering standards and multiple realistic constraints" in the (also required) curriculum-culminating major design experience

Standards do not specifically control product or process design, although they typically do provide sufficient guidance to skilled professionals to either ensure a reasonable factor of safety, and/or specify test procedures designed to disclose any safety issues that may exist. And while the application of such standards to engineering projects may not avoid liability in the event of personal injury due to failure or negligence, it is almost certain that the lack of application of available standards in case of injury will increase both the probability of being found liable as well as the magnitude of the resulting penalty [4].

Further, many consumer retail organizations will no longer carry product without applicable standards certification. Doing so may implicate the seller as well as the manufacturer in the event of injury and resultant determination of liability.

Two large standards organizations, ASTM and ANSI, both offer "introduction to standards" guidelines [5]. Why then, given the pervasive inclusion of standards in the practice of professional engineering, do some engineering students graduate 
from Engineering or Applied Science programs with little or no exposure to industry standards [4]?

\section{Teaching Standards: Case Studies from Queen's University}

One example of rigorous incorporation of engineering standards within engineering education is the Multidisciplinary Design Stream (MDS) in the Faculty of Applied Science at Queen's University [6]. As an elective offering to all engineering students at Queen's, the MDS begins with APSC 381 "Fundamentals of Design Engineering", a one term course with instruction in design methodology, tools and techniques, and a concurrent multidisciplinary team project. Modeled on engineering practice, industry standards are discussed in lecture material as an element of effective design process, and are required in the background research and chosen design for each team design project. In support for this requirement, an engineering librarian provides both an instructional lecture and ongoing assistance for teams in their search for relevant industry standards and other supporting information.

The MDS culminates with ASPC 480 "Multidisciplinary Design Project, an elective twoterm course with multidisciplinary student engineering teams working on significant projects with industry clients. Although guided by faculty supervisors and industry mentors, students are expected to consider all constraints related to their particular project - including both industry standards and regulatory codes. Supporting instructional material reinforces both the need and process for acquiring the necessary information, including additional assistance from engineering librarians. While students typically respond well to the need to identify and comply with relevant standards and codes, quick access is often difficult due to unavailability or outdated standards archives. In some cases the industry clients can provide access to relevant standards. However, when working on new developments, they too are unlikely to have relevant standards immediately available; hence the standards must be purchased on an as needed basis, typically at full commercial pricing. For appropriate educational purposes, students need full access to all relevant standards at prices affordable to educational institutions.

Engineering librarians work with students in the multidisciplinary design stream, senior design projects and in other appropriate courses in years 1 through 3. Last year we built an information research page for first year engineering to serve several courses. We covered web searching, technical books and articles, and simple patent searching, but decided not to include standards at this stage. Instead we opted to wait for upper -year courses. The decision to exclude standards stemmed from a sense that we couldn't and shouldn't introduce all types of information at once. As we prepare for fall '07 we are reconsidering which sources to include in the context of the particular projects that will be completed.

In APSC 381 the Integrated Learning Librarian meets students in their class at the stage where their teams are formed and their project assignments are finalized. We create a web course-guide for information research with links to resources. Although the guide sits on the library server it is linked directly from the course page. When we meet the students in class, we review a variety of information resources outlining what they are, how they are produced and why students might consider them in their projects. This is an active session in which most of the time is given to the students to work in their teams looking for the information they need for the project in hand. Because APSC381 is a prerequisite for APSC 480, our web guide for 480 [Figure 1] helps the students launch directly into their research. In the third year course we spend more time systematically reviewing a range of resources, notably standards and patents.

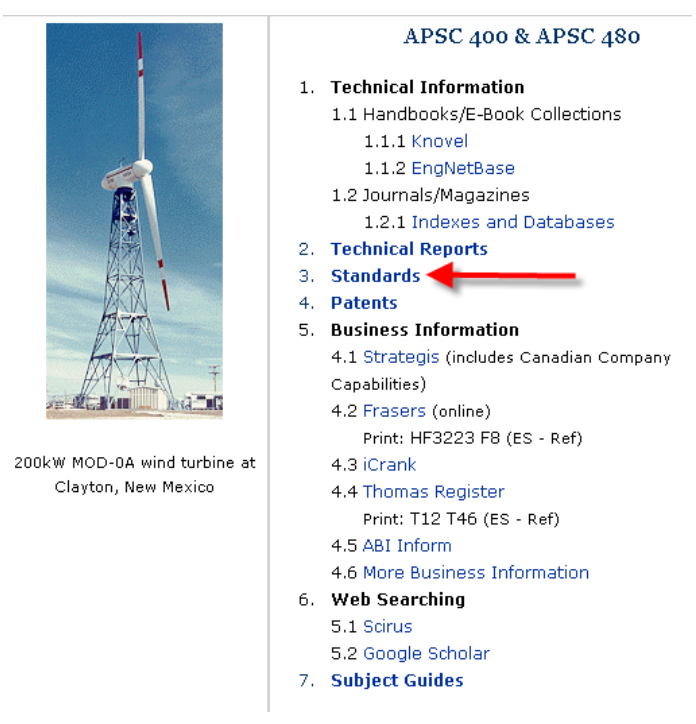

Figure 1. Course guide [7]

Of the types of information we include in this course, standards tend to be least known to our students. We define standards; review how they are created and by whom, including standards development organizations (SDOs); and look at how standards are reviewed, revised; and published. 
Finally, we tell students how they can get their hands on the ones they need. Sometimes students will know from their client or professor what standards to consider, while other times they are left to them to consider whether or not they need standards and if so, how to identify pertinent ones. To help with this we have created a standards guide from the online course-guide where we provide links to indexes that consolidate SDO inventories (e.g. Tech Street and Global Engineering Documents), to the University of Waterloo's excellent compilation of links to standards-writing organizations, and finally to a selected list of Queen's Library holdings.

In each of these courses, after the in-class session groups consult with librarians throughout the term.

\section{Teaching Standards: Case Studies from U. of $T$.}

As a senior lecturer at U of T's Department of Chemical Engineering and Applied Chemistry points out, much of the regulatory and associated material that $U$ of $T$ chemical engineering students designing for safety may need is freely accessible on the web. However, a significant problem for students is correctly locating what they need in this ocean of information. Introducing students to smart searching and providing a solid theoretical grounding is key, and the library can help to bridge this gap via selective instruction interventions as well as online help.

Graeme Norval [8] is a University of Toronto Department of Chemical Engineering and Applied Chemistry senior lecturer with extensive industry background who teaches in the areas of advanced reactor design, team strategies for engineering design, and process design. In a conversation earlier this spring, he identified several key challenges and described some of the standards and regulatory materials to which his students are currently exposed. $\mathrm{U}$ of $\mathrm{T}$ chemical engineering students are exposed in their third year to important materials from various Canadian government levels as well as selected US materials. Crucial Canadian materials at the national level include the Occupational Health and Safety Act (http://www.e-laws.gov.on.ca/DBLaws/Statutes/ English/90o01_e.htm) and the Workplace Hazardous Materials Information System (WHMIS) (http://www.hc-sc.gc.ca/ewh-semt/occuptravail/whmis-simdut/index_e.html/), as students learn how to read material safety data sheets.

One of the challenges in teaching in this context is to ensure that the students understand not just the legislation, but the relationship between legislation and associated regulations and standards. For example, there is the Environmental Protection Act and the associated regulated chemicals procedure, which is in itself standardized, and which shows you have met the standard. The task is further complicated by the fact that some of these materials are freely accessible while others are not.

An additional challenge for students searching for Canadian materials can be correctly understanding the government level at which the material is produced. A chemical engineering student searching for effluent treatment standards, for example, may take some time to correctly identify this as municipal-level information (Toronto Sewer ByLaw). And while Canadian environmental standards (air, water and land) are under provincial jurisdiction, Environment Canada also maintains a legislated reporting requirement, the National Pollutant Release Inventory (NPRI). This can give students three interrelated levels of environmental government regulations with which to grapple.

At the provincial level, $\mathrm{U}$ of $\mathrm{T}$ chemical engineering students may also need to know about materials such as the Ontario Government health \& safely publications produced by the Ministry of Labour. They are also beginning to be introduced to the sections of Ministry of Labour pre-start reviews relating to WHMIS (http://www.labour.gov.on.ca/english/hs/hs_pubs.htm l). In the course CHE334, Team Strategies for Engineering Design, students learn how to design for safety. They are introduced to US materials such as process safety reviews and, as part of the learning process, conduct a review. They may also be introduced to some materials which the library does not own, but which the department purchases. These include US National Fire Protection Association (NFPA) documents like the NFPA 68: Standard on Explosion Protection by Deflagration Venting, or materials produced by such bodies as the Chlorine Institute (e.g., Piping system for dry chlorine).

Useful library interventions for chemical engineering students could include summaries of materials accessible on the web both by topic and by government level, clarifying what can be found hardcopy in the library as compared to the web, and how it can be found. Basic orientations at first-year level plus more in-depth tutorial instruction as students enter fourth year are also key. As we'll see in section 9. below, the library has been working on a comprehensive my.library guide which will be available 24/7 and will help to orient all engineering students to materials available both in and out of the library. We have also be working to fill the gap at the first year level via sessions and a tutorial for a first year cross departmental core course. 


\section{SiE: CSA's Standards in Education}

For the 2007/2008 academic year we are anticipating the launch of set of tutorials from the Canadian Standards Association. The tutorials are part of a larger "program to encourage the teaching of standards and standards development into Canada's education system".[9] Along with the Royal Military College of Canada and the University of Quebec, Ecole de Technologie Superieure, Queen's University is participating in the creation of a set of tools and content directed at undergraduate engineering students. In response to the CSA's request for examples of specific courses in which students are exposed to and use standards and we selected the multidisciplinary design classes, APSC381 and 480 described above. Based on this needs assessment the CSA drafted a foundation tutorial - a set of resources, tools and exercises for the university partners to review. Foremost in our list of expectations for the tutorials is that students should learn through experience and that appropriate hands-on exercises and case studies be provided. We also anticipate being able to introduce students to tools that will make the current highly nonstandardized access to standards much easier. For example one tool cross references standards by subject area with the appropriate Canadian Standards Development Organization (i.e if you need a standard on sleeping bags visit the CGSB whereas if you are after solar collectors see the CSA). This summer a standards locator tool is under construction. This particular tutorial will help guide students to acquire the standard(s) they need.

Other primary concerns for Queen's are that the tutorials cover the principles of standardization rather than the specifics of select standards, and that they introduce students to the world of standards including and beyond the CSA. The drafts we have reviewed to date are meeting these criteria. However, tutorials can only be effective if students have access to standards for practical experience. Academic libraries play an essential role in this part of the standards equation.

\section{Access: Where Do Standards "Fit" Engineering Libraries' Collections? A Look at the Literature}

Industry standards pose particular challenges to collection policy, acquisition, material cost and access for libraries. A few US writers have attempted to define how libraries could best address these challenges, and have surveyed the ways that academic libraries in the US are coping with these materials.

This is not intended to be an exhaustive review of the relevant literature. Rather, we will briefly examine some common issues raised in a few recent studies as well as some of their findings and recommendations.

A common sense approach to collection policy development is stressed by one American author [10], beginning with a collection policy that states the role of standards within the collection, collection areas, levels, and primary user groups served. Beyond that, a hybrid approach combining standing orders and individual selection is recommended. Standing orders should be placed for such core materials as the Annual Book of ASTM Standards and major building, fire and trades codes. Individual selection is made in consultation with faculty and researchers. A careful approach is recommended with some of the larger standards producing organizations (ISO is an obvious example) to ensure a close fit between your institutional subject needs and the standards producers' very broad subject scope so standing orders will collect only within needed areas. In these situations selection on an individual basis may be necessary. A 2003 survey showed librarian mediated, on-demand purchasing to be a popular purchasing option for many ARL libraries [11].

End-user access to bibliographic records and to the materials themselves is another theme raised [10]. Bibliographic access, it is felt, determines usage levels, and where possible monograph level cataloguing is recommended while serials-level cataloguing is considered helpful. Physical collocation is also recommended as it raises visibility of standards and permits easy browsing.

The steady migration of scitech materials to online format is also seen in the standards literature, and this is seen by some as a good fit to our engineering user community's tendency to value desktop delivery [12], while others see on-demand purchasing as a more cost-effective strategy [11].

One author [13] examined access from a librarian's perspective. Librarians determining availability for purchase of specific standards or groups of standards on a particular topic need up-todate information on pricing, delivery, and content. Some broad based indexing services were compared, including IHS and ILI Infodisk as well as those of a number of individual organizations such as ANSI, ASTM and NSSN. To meet the dual challenge of cost effective access and timely acquisition, the author suggests that librarians subscribe to a standards database offering document delivery or online 
ordering or access. On the other hand, because individual organizations may offer more detailed or up to date information, as well as direct ordering, librarians are also advised to be open to this option and to develop an expertise with regard to the individual standards producing organizations. A final suggestion was that ILL agreements be made with other purchasing organizations.

A recent snapshot survey of top American engineering school libraries reviewed websites, posed a basic email reference question and surveyed subject specialists [12]. Findings indicate that industry standards continue to be a valued resource but financial constraints, interest level and limits to exposure result in underutilization, particularly among undergraduate students. Cost constraints remain a major challenge. A growing theme is the perceived need to go beyond providing simple access and to actively promote standards as valuable educational materials. This can be accomplished with a greater web presence, more information literacy interventions, and through the creation of more effective finding aids $[11,12]$.

\section{Survey of Canadian Academic Library Web Sites}

We wanted to get a preliminary indication of the importance Canadian academic libraries place on access to standards. In early summer 2007 we examined the websites of the libraries of the thirtysix accredited engineering schools in Canada to see whether or not they provide guides for accessing standards and, if so, how they are organized and what content is included. We found that 26 (72\%) of the libraries maintain at least one web guide on standards. We reviewed these for the following:

\begin{tabular}{|l|l|}
\hline Standards pages (N=26) & \\
\hline More than 1 page & $23 \%$ \\
\hline Link to SDOs & $\begin{array}{l}100 \\
\%\end{array}$ \\
\hline Define standards & $15 \%$ \\
\hline $\begin{array}{l}\text { Library holdings: described or "how to } \\
\text { find” }\end{array}$ & $62 \%$ \\
\hline $\begin{array}{l}\text { How to obtain (standards not in } \\
\text { collection) }\end{array}$ & $39 \%$ \\
\hline
\end{tabular}

Table 1. Standards pages on library web sites [14]

This snapshot suggests that libraries serving engineering faculties do consider these resources to be necessary to their students' learning and research. Every library links to a suite of standard development organizations (SDOs). At Queen's we provide such a listing for a number of reasons. It gives a visual cue to the scope of jurisdictions; we advise the students to confirm currency directly from the pertinent SDO and finally, many offer sale of standards directly from their websites. Some of us create subject specific pages (e.g. Standards for Civil Engineering) in addition to general standards pages. Most of us describe our institutions' holdings while fewer give explicit help on what to do if we don't have the needed standards. This may be because we assume the list of organizations is filling that need. It is interesting to note how few of us are brave enough to tackle the problem of defining standards. All of these observations beg more study.

\section{Access: Where Do Standards "Fit" Engineering Libraries' Collections? A Look at Queen's}

The Engineering \& Science Library serves learning and research in both natural and applied science at Queen's University. Queen's is a medium size (18,000 FTE) research university. The Library collects to support a full scope of engineering disciplines. We organize access to our purchased resources as well as open-access ones. Typical of technical collections we are purposefully building our electronic holdings across our suite of resources. In many ways standards are like all of our resources in that they need to be selected, acquired, stored and organized for access. And yet, as discussed above they pose unique problems for us to resolve.

The history of the Engineering \& Science Library explains some of the additional challenges we face here at Queen's. Just ten years ago ten departmental libraries were consolidated into one library. Each of those ten libraries had handled standards differently. When the collection was consolidated some standards arrived catalogued as monographs in the circulating book collection, some were catalogued as serials, and others parked themselves in the reference collection while a small army of uncatalogued standards was left isolated from the rest of the collection. At the same time many others were collected and organized in Queen's Library government documents collection (e.g. CGSBs). This didn't do much to help our students find them! We have made standards a collections priority in the last couple of years. The uncatalogued standards have been added to our catalogue on monograph records so they can be easily identified. An inventory of all our print standards is complete and we are in the process of measuring towards a goal of collocation. We want to 
mark these as special, and important and easy to find. As we organize the existing collection we are coming to terms with maintaining and strengthening the collection.

Collection policies guide our selections and although we don't have a collection policy for standards, we do include them in our departmental policies. By naming standards as a key format and matching it with the subjects we teach and research we hope to place the appropriate level of importance on them for the needs of distinct departments. We purchase the "usual suspects": IEEE/IEE via IEEE Xplore, ACI, ASTM, BPVC, ACI, etc. We purchase others, including such major bodies as CSA, ISO, ANSI and NFPA on a one-off /as needed basis. We buy standards on demand for our design teams and graduate students while we regularly solicit requests from our faculty. Like other libraries we are studying our use and purchase patterns to determine which type of buying is more efficient, this or package buying.

Because we buy electronically whenever we can, licensing is another major issue for us. Databases such as IEEE Xplore are of course limited to Queen's IP with proxy access. When we buy electronic copies as a "one-off" purchase we are storing them on our server behind the university proxy to ensure use by our community only. We insist on fair use for our academic community when we review licenses. Like many of our colleagues we await license terms and pricing for the CSA e-library.

We want to make access to standards as easy as possible. Certainly cataloguing our holdings is key to achieving this. Likewise we consider well constructed web guides equally important. This is because we know that no matter what standards we have in the catalogue, our students and faculty will need some that we don't own. We are also one of the few libraries maintaining multiple web pages, including a general page, plus others for departments and some for specific courses. User studies will tell us if this is the best approach.

As described earlier we weave standards into our information literacy program. We don't give general "how to find standards" sessions, but instead select courses in which the students have projects requiring them to consider standards. If we are going to teach students that standards are important and if we want them to learn through experience, then we had better have a solid collection.

\section{Access: Where Do Standards "Fit" Engineering Libraries' Collections? A Look at $\mathbf{U}$ of $\mathbf{T}$}

\author{
Engineering and Computer Science Library at \\ University of Toronto
} (www.library.utoronto.ca/engineering-computer-

science) serves a large, diverse, research-intensive faculty made up of 4,700 undergraduate students, 1,300 graduate students and over 200 faculty members spanning the gamut of engineering disciplines.

Our collection includes over 200,000 monographs, 1,400 current periodical subscriptions. Our standards and codes collection is the most complete in the Greater Toronto Area, and is an important resource not just for our primary University of Toronto community but also for external users such as professional engineers, law firms, lay persons and students from other Ontario engineering schools.

Like many libraries, and like some of the American authors described above, we have opted for a hybrid solution to purchasing standards. Rising costs of these and other materials have resulted in some difficult choices. Our standards and codes collection is still mostly in hardcopy. In some cases, such as the Ontario Building Code and CSA Standards, they are not yet available in electronic form. In other cases, such as the Annual Book of ASTM Standards, cost is a deciding factor. Package purchases can save considerable staff time, but we have also noted the cost disadvantages of packages described by others $[4,5]$.

Our collection development policies are subject rather than resource or format based and this is true of standards. We do not have a specific policy for collecting of these types of materials. Rather, beyond certain core collections, we collect a wide range of materials to support the research and teaching needs in given subject disciplines.

For core standards collections such as CSA and the Annual Book of ASTM Standards, we maintain hardcopy standing subscriptions. We also maintain a subscription to CGSB standards. From ASME, we purchase the Boiler and Pressure Vessel Code in hardcopy, but other ASME standards are purchased individually on-demand. In the past efforts were made to purchase ISO standards but in recent years rising costs have made this increasingly difficult. We keep all superseded standards and codes, and our historical collection also includes selected standards from such organizations as ANSI, SAE, ASCE, UL, DIN, IEC and many others. We maintain an online subscription to IEEE standards via the IEEE Xplore. 
Where we do not own a standard, and where it is financially possible, we make every effort to fill requests from our primary user community for needed standards by purchasing on-demand. We purchase the National Construction Codes online and the National and Ontario Building Codes in print, though we would welcome the availability of the OBC in online format. We also purchase other important codes such as fire, plumbing and electrical.

We share some of the access and promotion concerns raised by other authors $[5,6]$ but staff time has been a serious constraint. To help our users find standards, we maintain a simple web page which describes in general terms standards and codes, major standards-producing organizations, and a brief outline of our holdings. Over the years we have maintained information on our complete standards holdings in a hardcopy binder accessible to reference staff, and as staff time permits we are working to transfer this information to an online my.library guide which will accessible to all users from our web page. For the moment, we maintain links to the existing page from all subject-specific research guides. We also include additional instructional information in course-specific my.library guides such as the first year APS112 guide. We maintain online searchable databases of our CSA and CGSB standards holdings and are working on a similar searchable database for our ISO collection..

All our standards and codes are catalogued though ease of searching via the catalogue varies widely and this admittedly creates problems for our patrons. Some collections (e.g., ASME standards, ISO handbooks) are catalogued as monographs while others (e.g., CSA) are catalogued as serials. Users searching for individual standards in the catalogue may thus find them, or they may not. An additional complication is that ISO handbooks collect many individual standards into a single handbook so a catalogue search will also be unsuccessful in this case. We are attempting to overcome some of these limitations with the searchable databases described above.

At the moment we do not offer instruction sessions specific to these materials but rather include information on standards and codes in class- or assignment-specific workshops as appropriate. Fall orientations and on-demand orientations do however include our standards and codes collections.

All our current standards and codes are kept together as a subset of our reference collection, though a couple of high-demand codes are kept in our Short Term Loan collection. Superseded standards are considered an important part of our collection and are never discarded.
Like most institutions, $\mathrm{U}$ of $\mathrm{T}$ does not loan its standards and codes via interlibrary loan. When we need a standard we do not own, we need it quickly and so we generally do not attempt an interlibrary loan which might be quite time consuming. Instead, we try to purchase the standard and process it as quickly as possible.

\section{Standards Council of Canada Program}

A useful but not well known cost-saving alternative now available to Canadian university and college libraries is the Standard Council of Canada's new Educational Institution policy. Since January 2006, SCC has offered professors and students free online access to ISO and IEC standards for use in an accredited course curriculum. Since ISO standards, for example, can cost anywhere from $\$ 50$ to $\$ 150$ and upwards each, significant cost savings are possible through this program.

The program began with Ecole de technologie superieure, a member of the Universite du Quebec network, and has grown, largely by word of mouth, so that 11 institutions are now subscribed, including the Universities of Toronto, Dalhousie, Guelph, UBC, and BCIT [10]. The program is still in planning stages and has not been widely advertised yet, but is available to any Canadian post secondary institution that applies, as long as certain requirements are met. SCC's goal is to extend the program eventually to all universities and colleges in Canada. University of Toronto Libraries have subscribed to the program for the past two years. Though some access wrinkles have had to be worked out from time to time, significant cost savings have already been possible.

\section{Conclusion}

For effective learning students need both exposure to the principles of standards / standardization and access to standards for practical experience. Queen's University and the University of Toronto provide examples of how engineering curricula and library collections are endeavoring to address these issues. We hope this paper opens collaborative study across Canadian schools where we share accreditation criteria, regulatory jurisdictions and copyright law.

\section{References}

[1] Gerrard G. Lowen et al, ASME Codes and Standards: Examples of Use for Mechanical Engineering Students, ASME International, New York. 
[2] Canadian Engineering Accreditation Board, Accreditation Criteria and Procedures 2006.

See:http://www.engineerscanada.ca/e/files/report ceab.pdf

[3] ABET, Criteria for Accrediting Engineering Programs. See:

http://www.abet.org/forms.shtml\#For_Engineering_Progra ms_Only

[4] Richard E. Forbes and Mary C. Emplaincourt, "Engineering Standards and Product Liability", Proceedings of the 2003 American Society for Engineering Education Annual Conference and Exposition, ASEE, Nashville, June 2003.

[5] William E. Kelly, "Incorporating Engineering Standards in the Major Design Experience”, Proceedings of the 2003 American Society for Engineering Education Annual Conference and Exposition, ASEE, Nashville, June 2003.

[6] David S. Strong, "The Multidisciplinary Design Stream at Queen's University”, Proceedings of the 2005 Canadian Design Engineering Network Conference ,Kananaskis, June 2005

[7] APSC 400 \& APSC 480 Course Guide: Information Research

(http://library.queensu.ca/webeng/guides/APSC400/APSC4 00_ind.htm)

[8] Conversation with Graeme Norval, March 28, 2007.

[9] Email correspondence with Gregory Skinner, Canadian Standards Association, June 12, 2007

[10] D. Taylor. "Standards collection development in an academic library," Collection Building, vol. 18, iss. 4, pp. 148- , 1999.

[11] L.J. Pellack. "Industry standards in ARL libraries: electronic and on-demand," Collection Building, vol. 24, iss. 1, pp. 20-28, 2004.

[12] B.S. Matthews, “The Role of Industry Standards: An Overview of the Top Engineering Schools' Libraries”, Issues in Science and Technology Librarianship, Association of College and Research Libraries, Spring 2006. Accessed online June 19, 2007 at: http://www.istl.org//06-spring/refereed.html

[13] M.C. Schlembach. "Access to standards over the web: a comparison of searching services," Science \&

Technology Libraries, vol. 19, iss. 2, pp. 53-74, 2001.

[14] Data compiled June 8-11 by Janet Burgess, Engineering \& Science Library, Queen's University. Please contact us for the complete study.

[15] Conversation with Anne Sharkey, Information Resource Officer, Standards Council of Canada, June 13,
2007. Institutions interested in the program can contact Anne Sharkey for more information at 613238-3222 ext 460, asharkey@scc.ca 